\title{
Building LGBTQ awareness and allies in our teacher education community and beyond
}

\author{
Dr. Laura-Lee Kearns, Saint Francis Xavier University \\ Dr. Jennifer Mitton Kukner, Saint Francis Xavier University \\ Dr. Joanne Tompkins, Saint Francis Xavier University
}

Abstract

In this article we share the impact of a training program (Positive Space I and Positive Space II) on pre-service teachers' understandings of and abilities to create safe spaces for Lesbian, Gay, Bi-sexual, Transgendered and Queering/Questioning (LGBTQ) youth and allies in our teacher-education program and in schools. Research has demonstrated LGBTQ youth are more likely to feel unsafe, alienated and more vulnerable than their heterosexual counterparts in schools and society. Our discussion focuses upon the impact of this training program, and considers challenges and best practices to build awareness and allies in our own highereducation context, as well as to help create better learning communities for LGBTQ youth and allies in schools. We suggest this particular program is an example of how to work towards the development of a pedagogy that does not oppress; one that truly embraces, celebrates, and honours all learners.

\section{Introduction}

Research has demonstrated that over $75 \%$ of Lesbian, Gay and Bi-sexual youth and $95 \%$ of Transgendered students do not feel safe at school compared to $20 \%$ of heterosexual students (Taylor et al, 2011, 47). The current bullying discourse does not often highlight the vulnerability of sexual minority youth. According to the First National Climate Survey on Homophobia in Canadian Schools (Taylor et al, 2009) "homophobic and transphobic bullying are neither rare nor harmless but major problems that schools need to address" (p. 2). The Canadian Charter of Human Rights and Freedoms, provincial equity policies, school and school board policies and curricula emphasize "human rights and diversity" however, "LGBTQ students feel unsafe, insulted or harassed," on a daily basis (Taylor as cited in Petz 2011). Compounding this issue is the reality that LGBTQ youth hear and see a lot of homophobia and transphobia in schools, and they don't see adults in leadership positions interrupting this type of discrimination (Goldstein et al, 2007; Kumashiro 2002; Taylor et al, 2011). This is particularly regrettable as research also shows that "the climate is significantly better in the schools that have taken even modest steps to combat homophobia" (Taylor, 2011, para 4). To that end, we are trying to promote anti-oppressive pedagogy as part of our approach to teaching and learning in our faculty of education.

Here we share the impact of a training program, Positive Space I (PSI) and Positive Space II (PSII), two three-hour workshops, that have been integrated into 
mandatory education classes, Sociology of Education and Inclusion I, which and help to promote pre-service teachers' understandings of and abilities to create safe spaces for LGBTQ youth. The purpose of our study is to explore the impact of this training program, and to consider challenges and best practices to build awareness and allies in our own higher-education context, as well as to help create better learning communities for LGBTQ youth and allies in schools. Our Positive Space Training program is also critical as many future teachers are not prepared to address "issues of homophobia and heterosexism in the classroom" (Stiegler, 2008, p. 117). By honouring our students and helping them become "activists" who may help advance "academics and social justice" (Kumashiro, 2002, p. 13), we hope to better inform not only our own practice but also that of the field of higher education.

Our teacher education faculty is situated within St. Francis Xavier University in rural Atlantic Canada. Our Bachelor of Education is a two-year program, with approximately 240 students. Prior to 2009, PS I \& PS II were voluntary. Since 2009 it has been institutionalized as part of our B.Ed program in courses that discuss issues around power and privilege, and interlocking forms of oppressions. Positive Space I features awareness building with a focus on language and terminology and Positive Space II focuses on becoming an ally, which gives the opportunity for preservice educators to witness and role play educators interrupting heteronormativity. Recognizing that "a lack of a solid Canadian evidence base has been a major impediment faced by educators who need to understand the situation of ...LGBTQ students in order to respond appropriately" (Taylor et al., 2009, p. 2), sharing our work is timely and necessary. As a further impetus, we also recognize that in addition to feeling unsafe, rural LGBTQ youth have been shown to experience more hostile climates than their urban counterparts compounded by fewer resources and supports, including a lower prevalence of Gay Straight Alliances (GSAs), supportive staff, inclusive curricula, and comprehensive anti-bullying policies (GLSEN Report, 2012).

\section{Data collection}

This paper describes the Positive Space training program and its relationship to our teacher education program. It highlights findings from workshop evaluations of Positive Space I and II provided by participants 2010-2012, incorporates findings from pre and post training on-line surveys in 20112012 , and follow up interviews with individuals and a small focus group in 2013.

\section{Themes Arising From the Data}

\section{On the need to create LGBTQ awareness}

There is a broad range of awareness and understanding of LGBTQ realities among our pre-service teachers. In the pre-survey at the very beginning of their B.Ed in September, in response to the question, "Have you ever had any 
previous training in LGBTQ issues?" 84\% of respondents said "No". Of the $16 \%$ who said "Yes", some said they had friends or parents who identified as LGBTQ. And others had taken Positive Space training as part of women's studies programs. In response to the question, "When you were in school, was there a Gay Straight Alliance (GSA)?" 13\% said "Yes", 74\% said "No" and 16\% wrote that they were unsure. In response to "Have you ever had the experience of participating in any LGBTQ event?" 24\% said "Yes", and 76\% said "No" (PreTraining Electronic responses Fall 2011). For those who said "Yes", the events listed, included mostly Pride parades and same sex weddings. Although workshop feedback and pre-survey data showed that some pre-service educators self-identified as allies who wanted more critical discussions on these issues, we found it surprising that a majority of pre-service teachers would not have had the opportunity to engage with the LGBTQ community. All of this information is insightful, as it indicates that both formally and informally pre-service educators need support and explicit LGBTQ training to engage with anti-oppressive pedagogy.

\section{Positive impact of the training}

The training proved to be important on multiple levels. Many participants said it helped with their confidence in terms of awareness about the challenges some LGBTQ individuals face. As one participant shared, the training "opened my eyes to issues I hadn't thought of before... [I didn't] recognize the severity and impact [homophobia] might have [on LGBTQ youth]" (Interviewee 7). The training not only created more understanding about the challenges LGBTQ individuals face, it clarified language and terminology, and also helped people recognize and examine the privilege of heterosexuals. It created a way to discuss complex issues and also showed the importance of interrupting homophobia. One participant shared "my awareness of LGBTQ issues and comfort intervening when I witness a homophobic act is much greater since taking these Positive Space Training sessions" (Postsurvey electronic response-Winter 2012). Further, we learned that without this specific training, some pre-service educators may not have seen responding to the needs of LGBTQ or human rights advocacy as part of their professional responsibilities. As one interviewee shared, prior to the training "sexuality wasn't big on my radar for school because I was so worried about ... [having] a good lesson" (Interviewee 8). The interviewees also shared that since many had not participated in GSAs in their own schools, they said the training was critical to understanding what they were and that everyone was welcome to be an ally. Certainly, pre-service educators found it is important to consciously name discrimination and weave ways to address homophobia in our program.

\section{Lack of understanding of what it meant to interrupt}

Although the pre-service teachers we worked with emphasized the importance of learning more about how to create and sustain positive spaces for LGBTQ youth and allies in schools, a common thread emerging from follow-up focus group 
interviews was their lack of understanding of what it meant to interrupt situations of a discriminatory nature. For example, one pre-service teacher, in describing his action of crossing out the word 'gay' that had been negatively written over a Positive Space sticker in a school washroom, commented, "I don't know if that was appropriate but at least they [LGBTQ youth] don't have to see it... I guess that's a step in the positive direction." Some of the pre service teachers' uncertainty about interruptions and their seeming lack of understanding about the power of small actions, as seen in our previous example, may be connected to their prior experiences as learners in schools, or imagining that anti-discrimination actions need to be extraordinary, or their field placement experiences in which they witnessed few examples of anti-oppressive pedagogy. For us, these discussions helped us recognize that we need to highlight the power of small, ongoing interruptions as part of pre-service teachers' understanding of anti-oppressive pedagogy and the ways it might inform their work in schools.

\section{Power imbalance}

Our follow-up interviews also showed that issues of power impact the sense of agency our pre-service teachers feel as they attempt to interrupt homophobia and transphobia. On one level there is a power imbalance between pre-service teachers and their cooperating teachers. They are student interns working alongside mentor teachers. The relationship is meant to be of mutual benefit. Though, there is an imbalance; the opinions of the licensed teacher hold some weight in the student's evaluation and potentially future employment prospects. It is a power relationship of which our pre-service teachers are highly aware: "the power structure is against us in a variety of ways. We want to have good references and ...do a good job... all those things conflict depending on who your CT is.... my career is at stake" (Interviewee 4). This power dynamic can also be a problem for some pre-service teachers who want to interrupt homophobia when the cooperating teacher does not. One student explains: “... I had a student pass a note to another student and it had faggot written on it ...And I couldn't think of a way to approach the class about it and my CT didn't want to deal with it..." (Interviewee 1). Reflecting back on the incident, the student teacher said "it's hard being a student teacher" and asked "...how do I make this work"? Though several pre-service teachers felt supported to act as an ally, others worried that their attempts to challenge homophobia and heteronormativity could be viewed negatively and felt limited to act as an ally.

\section{The gender binary: Responding and interrupting}

It was clear that the gender binary, a system of overtly and covertly naming and stereotyping differences between boys and girls is learned and reproduced by schools. Our follow-up interviews showed our pre-service teachers grappling with just how profound this binary is instilled and trying to find ways to disrupt or work within it. For example, one interviewee in our focus group shared that she would try to show the grade primary class "non-gendered pictures" and the 5 and 6 year olds "would ask is this a boy or a girl and how can you tell" (Interviewee 3 ). The 
pre-service teacher would think to herself, "it doesn't matter it's just a [picture]". Yet she understood that "it was all the systems that they grew up with and what they were used to... boys wear pants boys and shirts... and... [to] try and break an entire system... It's really difficult." The boy and girl codes though deeply entrenched, were recognized by this pre-service teacher, who at least wanted to start doing "small things" to open up more possibilities. In her context, she "started asking 'are you a boy or are you a girl? It's your choice, I'll put down whatever you tell me you are." At the secondary level the importance of gender was also at the fore. One interviewee shared that in the social studies classroom there were more opportunities to discuss human rights, but in the physical education classroom, where there was still a lot of "boys vs girls" it was more challenging. This one student teacher had a transgender student in his class, so in order to respond, he asked the student which team s/he preferred to play on: "I'd let [James] play on the girls team if he wanted to" (Interviewee 8). Pre-service teachers are engaged in the gender binary in schools daily, some are trying to complicate it, disrupt it or simply adhere to it in different ways.

\section{Implications : Continuing our work in Higher Education}

Our study has substantiated some of what we know about the importance of including LGBTQ in higher education programs (Goldstein et al., 2007; Kitchen \& Bellini, 2012; Taylor et al., 2009, 2011). Our research also shows that by taking part in the training, pre-service teachers felt they were more capable at supporting LGBTQ youth, colleagues, people and/or participating in GSAs. Key themes that emerged in our data and which we note as different from other studies is the lack of understanding that pre-service teachers had about small interruptions as being an important part of their anti-oppressive pedagogy. We also note how they were able to identify the gender binary as a presence in schools and curriculum, and the choices they made in such situations with actions that they felt enabled students to have broader choices about who they felt themselves to be. While we emphasize the positive impact of the training, we also note that participants expressed concerns about how much they were able to do in schools in relation to LGBTQ work, putting particular emphasis on a power imbalance between themselves and their cooperating teachers. Several participants also mentioned that they wanted more training opportunities, and in response we are planning a Positive Space III and IV. Our efforts will continue to focus on ways to support opportunities for future, early career, and experienced teachers to create inclusive spaces in schools.

\section{Conclusion}

As a result of positive space training teacher candidates' awareness of LGBTQ issues has increased and they are developing a vocabulary to name heterosexism and identify instances in which they should intervene to interrupt homophobia and transphobia. Importantly they are developing the skills to proactivily create inclusive environments. Results also indicate areas for further growth, particularly in pre-service teachers' sense of efficacy to act as allies. The opportunity for 
teacher candidates to understand how to incorporate anti-discrimination work in their teaching practice is a key component of school and education reform. Social justice policies and procedures exist in many school settings, but unless new teachers have the opportunity to explore and apply their grounded knowledge from professional development, these well-meaning policies are often neglected or ignored. We suggest that this particular program is an example of how to work towards the development of a pedagogy that does not oppress; one that truly embraces, celebrates, and honours all learners.

\section{References}

GLSEN (2007). Gay-straight alliances; creating safer schools for LGBTQ students and their allies (GLSEN research brief). New York: Gay, Lesbian and Straight Education Network.

Goldstein, T., Russell, V., \& Daley, A. (2007). Safe positive and queering moments in teaching education and schooling: A conceptual framework. Teaching Education, 18(3), 183-199.

Kitchen J. \& Bellini, C. (2012). Addressing lesbian, gay, bisexual, transgender, and queer (lgbtq) issues in teacher education: Teacher candidates' perceptions. Alberta Journal of Educational Research, 58(3), 444-460.

Kumashiro, K. (2002). Troubling education: "Queer" activism and anti-Oppressive pedagogy. New York, NY: Routledge.

Stiegler, S. (2008). Queer youth as teachers: Dismantling silence of queer issues in a teacher preparation program committed to social justice. Journal of $L G B T Q$ Youth, 5(4), 116-123.

Taylor, C., Peter, T., Schachter, K., Paquin, S., Beldom, S., Gross, Z., \& McMinn, T. L. (2009). Youth speak up about homophobia and transphobia: The first national climate survey on homophobia in Canadian Schools. Phase one report. Toronto, Canada: Egale Canada Human Rights Trust.

Taylor, C., \& Peter, T., with McMinn, T.L., Elliott, T., Beldom, S., Ferry, A., Gross, Z., Paquin, S., \& Schachter, K. (2011). Every class in every school: The first national climate survey on homophobia, biphobia, and transphobia in Canadian schools. Final report. Toronto, ON: Egale Canada Human Rights Trust. Available from http://www.egale.ca/index.asp?lang=E\&menu=1\&item=1489

Taylor, C. (2011). Homophobia creates hostile world for Canadian students [Press release]. University of Winnipeg. Retrieved from http://www.uwinnipeg.ca/index/uw-news-action/story.572/title.homophobiacreates-hostile-world-for-canadian-students 